\section{AB0511 EFFECT OF SECUKINUMAB ON THE REDUCTION OF MYOCARDIAL DYSFUNCTION IN PATIENTS WITH ANKYLOSING SPONDYLITIS}

S. Lapshina ${ }^{1}$, L. Feiskhanova ${ }^{1} .{ }^{1}$ Kazan State Medical University, Department of Hospital Therapy, Kazan, Russian Federation

Background: In ankylosing spondylitis (AS), early subclinical changes in the myocardium mostly remain undiagnosed. The impact of genetic engineering biological therapy on these changes is also unclear.

Objectives: Aim: to establish the relationship between taking of secukinumab and changes in systolic and diastolic myocardial function in patients with AS. Methods: 69 patients with AS were examined, of which the first group included 33 people (average age $38.8 \pm 4.74,63.6 \%$ of men) who received the interleukin 17 inhibitor (IL17) - secukinumab, the second group - 36 people who did not receive biological therapy, average age $42.5 \pm 11$ years, $66.7 \%$ of men. The control group included 40 healthy individuals, comparable in gender and age. Patients underwent tissue dopplerography of the heart and transthoracic echocardiography. The research materials were subjected to statistical processing using the program STATISTICA 10.0 .

Results: The patients with AS had significantly higher left ventricular mass index and ejection fraction $(p<0.01)$ compared to the control group. Moreover, among patients who do not take biological therapy, the indicators were the highest (tabl.1).

Table 1. Comparison of transthoracic echocardiography parameters in the study groups according to the Craskell-Wallis test.

\begin{tabular}{lcccc}
\hline Показатель & group 1 & group 2 & control group & $\mathrm{p}$ \\
\hline LVMI & $85[81 ; 100]$ & $93[81,3 ; 114,2]$ & $79,5[72 ; 86,5]$ & $\mathrm{p}=0,002$ \\
$E F$ & $63[62 ; 64]$ & $64,5[63 ; 66]$ & $60[59,5 ; 64,5]$ & $\mathrm{p}=0,003$ \\
\hline
\end{tabular}

LVMI - ventricular myocardial mass index, EF - ejection fraction.

A comparison of tissue dopplerography of the heart between the groups established statistically higher values of peak velocity of the ring of the mitral valve in early diastole (e'L) in the 1st group $(14[9,5 ; 14])$ and control $(13[11 ; 15,5])$ compared with the indicator of the second group $(10,5[8,3 ; 13]), p<0,01$; the peak speed of movement of the septum in early diastole, (e'S) in patients with secukinumab is higher $(11[9 ; 11])$ compared to 2 th $(8.1[7 ; 12])$ and control groups $10[8.5 ; 11]), p<0.05$, and in the 2nd group lower than in the control $(p=0.03)$. Significant differences in the parameters were supported by a comparison of the frequency of detection of diastolic dysfunction in the study groups. Diastolic dysfunction was diagnosed only in this group - in $38.9 \%$. Against the background of the use of secukinumab, an increase in the systolic function of the myocardium was revealed.

Conclusion: The patients with AS are characterized by a high frequency of subclinical heart dysfunction. Inhibition of IL17 can reduce diastolic dysfunction, which is confirmed by an improvement in myocardial contractility during secukinumab therapy.

REFERENCES:

[1] ankylosing spondylitis, spondylarthritis, diastolic myocardial dysfunction, secukinumab

Disclosure of Interests: None declared.

DOI: 10.1136/annrheumdis-2021-eular.3474

\section{AB0512 CLINICAL AND RADIOLOGICAL FEATURES OF SHOULDER INVOLVEMENT IN SPONDYLARTHRITIS}

C. Ines ${ }^{1}$, H. Ferjani ${ }^{1}$, K. Maatallah ${ }^{1}$, S. Miri ${ }^{1}$, H. Hajji ${ }^{1}$, M. Yasmine ${ }^{1}$, D. Kaffel ${ }^{1}$ W. Hamdi' on behalf of Rheumatology department of Med kassab institute of orthopaedics.. ${ }^{1}$ Manouba, Rheumatology, Mannouba, Tunisia

Background: Peripheral joint involvement is frequent among patients with peripheral spondylarthritis (SA). However, the root joint involvement, such as hip involvement, has been described as being associated with axial spondylarthritis, while data for shoulder involvement are scarce. Cuff tendonitis and enthesitis are common features in the shoulder in patients with SA.

Objectives: This study aimed to identify the prevalence of shoulder involvement in SA patients and describe its clinical and radiological features.

Methods: We conducted a retrospective study including SA patients, all fulfilling the assessment of Spondyloarthritis International Society (ASAS) criteria.

For all patients, we collected the following data: Age, the clinical presentation of $\mathrm{SA}$, the inflammatory biomarkers $\mathrm{C}$-reactive protein (CRP), and the disease activity assessed by the Bath Ankylosing Spondylitis Disease Activity Index (BASDAI).

Regarding shoulder involvement, we assessed the following items: tenderness, mobility, rotator cuff tests, as well as the results of X-ray and Ultrasound examination (US).
Results: We included one hundred and thirty-one SA patients (mean age 39,77 years). Among them, sixty-two percent were male. Ten percent of patients were smokers, $46,6 \%$ had the peripheral beginning of the disease. Fourteen patients complained of shoulder pain. The majority of them were male.

$X$-rays showed no abnormalities $(n=2)$, while a destructive form was noted in $(n=7)$.

Rotator cuff rupture or enthesopathy was also revealed by the reduction of subacromial space $(n=5)$, condensation of the greater tuberosity $(n=3)$, crooked aspect of the acromion ( $n=2)$, and Moloney's line disruption $(n=1)$.

US showed no abnormalities $(n=1)$, supraspinatus tendinopathy $(n=5)$, supraspinatus transfixing tear $(n=1)$, infraspinatus tendinopathy $(n=2)$, supraspinatus enthesopathy $(n=2)$, infraspinatus enthesopathy $(n=1)$, moderate synovitis $(n=1)$, subacromiodeltoid bursitis $(n=1)$.

Shoulder involvement was correlated significantly with the peripheral beginning of SA $(P<0.05)$. There were no significant differences in gender, tobacco use CRP value, and the disease activity between the two groups $(P>0.05)$.

Conclusion: The shoulder involvement was rare in our study. It is characterized by cuff tendonitis and enthesitis, especially in supraspinatus insertion. However, the glenohumeral synovitis was uncommon in our series, even in the peripheral form of the disease.

\section{REFERENCES:}

[1] Hip and Shoulder Involvement and Their Management in Axial Spondyloarthritis: a Current Review Clementina López-Medina1,2,3,4 \& M. Carmen Castro-Villegas1,2,3 \& Eduardo Collantes-Estévez1,2,3, 23 July 2020.

Acknowledgements: I would like to thank all the authors listed above, for they helped me make writing my first abstract less harder.

Disclosure of Interests: None declared.

DOI: 10.1136/annrheumdis-2021-eular.3503

\section{$\mathrm{AB} 0513$}

\section{THE RELATIONSHIP OF PERIARTICULAR TISSUES LESIONS AND JOINTS DEGENERATIVE CHANGES IN PATIENTS WITH INFLAMMATORY BOWEL DISEASES}

G. Gainullina ${ }^{1}$, E. Kirillova ${ }^{1}$, D. Abdulganieva ${ }^{1}$, E. Belousova ${ }^{1}$, A. Odincova ${ }^{2}$.

${ }^{1}$ Kazan State Medical University, Therapy, Kazan, Russian Federation;

${ }^{2}$ Republican Clinical Hospital, Gastroenterology, Kazan, Russian Federation

Background: Inflammatory bowel diseases (IBD) are associated with a variety of extra-intestinal manifestations. The most frequent of these is joint involvement which affects $16-33 \%$ of IBD patients, whereas $5-10 \%$ are affected by enthesitis $[1,2]$. Recent studies have shown the superiority of ultrasound over clinical findings in the evaluation of joints and periarticular tissues [3].

Objectives: To assess of joint and entheseal involvement in patients with Crohn's disease $(C D)$ and ulcerative colitis (UC) using ultrasound with Power Doppler.

Methods: We prospectively included 70 IBD patients into the study. Periphera joints and entheses were imaged by ultrasound, using Samsung Accuvix A30 5-13 MHz linear array transducer. Ultrasound examination of 14 peripheral joints (hip, knee, ankle, shoulder, acromioclavicular, elbow, wrist) and 35 entheses was performed. Vascularization was assessed with Power Doppler (PD). Statistical analysis was done by Mann-Whitney test by "Statistica" software.

Results: In 70 patients UC was in 40 (57\%), CD - in 30 (43\%). The mean age of patients was $32(27 ; 36)$ years. The mean duration of the disease was $48(12 ; 84)$ months. The majority of patients had highly active disease: moderate and severe activity was observed in 47 (67\%).

Osteophytes were found in 32 (46\%) IBD pts, in 10 pts (14\%) - osteophytes were found in three or more joints. We divided pts into two groups. In first group we included pts without degenerative changes in the joints, in the second - with identified osteophytes.

Osteophytes were found more often in the acromioclavicular joints - 13 pts ( $41 \%)$ and in the hip joints - 10 pts $(31 \%)$. With the same frequency ( 9 pts), osteophytes were detected in the wrist, knee and ankle joints. The mean age of pts and mean duration of IBD were significantly higher in the second group patients $(p=0.00002$ and $p=0.019)$.

Enthesitis (echogenicity reduction and thickening) without vascularization were detected in 26 patients of the first group $(68 \%)$ and 29 patients of the second group $(91 \%)$ ( $p=0.009$ ). The rate of vascularized enthesitis in the two groups was the same: enthesitis with vascularization were observed in 14 pts of the first group (37\%) and 14 of the second group $(44 \%)(p=0.822)$. Structure damage (erosions and enthesophytis) was more frequent in the second group $(p=0.025$ and $p=0.001$ ). There were no significant differences in the incidence of tendinitis and tenosynovitis between two groups.

Conclusion: Joint and periarticular tissues damage in IBD patients increases with age and duration of the disease. The presence of degenerative changes in the joints is associated with more frequent detection of enthesitis and enthesopathies.

\section{REFERENCES:}

[1] The First European Evidence-based Consensus on Extra-Intestinal Manifestations in IBD. JCC. 2016; 10 (3): 239-254. 
[2] Rovisco J, Duarte C, Batticcioto A et al. Hidden musculoskeletal involvement in inflammatory bowel disease: a multicenter ultrasound study. BMC Musculoskelet Disord. 2016; 17: 84.

[3] Yu-Fen Hsiao, Shu-Chen Wei, Cheng-Hsun Lu et al. Patients with Inflammatory Bowel Disease have Higher Sonographic Enthesitis Scores than Normal Individuals: Pilot Study in Taiwan. Journal of Medical Ultrasound. 2014 Dec; 22(4): 194-199.

Disclosure of Interests: None declared.

DOI: 10.1136/annrheumdis-2021-eular.3520

\section{AB0514 PRELIMINARY DATA ON THE STUDY OF THE POSSIBILITY OF USING ULTRASOUND TO OBJECTIFY THE MOBILITY OF THE SPINE IN ANKYLOSING SPONDYLITIS}

M. Kurbanmagomedov ${ }^{1}$, K. Sakharova ${ }^{1}$, A. Demina ${ }^{1}$, S. Erdes ${ }^{1}$. ${ }^{1}$ V. A. Nasonova Research Institute of Rheumatology, Moscow, Clinic, Moscow, Russian Federation

Background: Spinal damage with limited mobility requires the search for diagnostic methods that allow us to accurately and quantitatively assess the developing decline in function and track this change in dynamics. One of these possible methods is ultrasound examination of the spine, which was recently described in the article Yurdakul O. V. [1].

Objectives: to study the possibility of using ultrasound for dynamic monitoring of sagittal mobility of the spine in ankylosing spondylitis (AS).

Methods: Ultrasound of the spine was performed in 15 patients with AS according to the method described in the article Yurdakul O. V. - determination of the sonographic distance between the spinous processes C5-C6, Th11-Th12 and L4-L5 of the vertebra (initial - vertical position, and when tilted - maximum sagittal flexion). All patients underwent a double examination: at inclusion in the study and after 2 weeks. The average age of the patients was $40.8 \pm 11.4$ years, and the average duration of the disease was $5.5 \pm 3.5$ years. $93.3 \%$ of patients were positive for HLA-B27. All patients were treated with nonsteroidal anti-inflammatory drugs, and $9(60 \%)$ had biological therapy. The differences $(\Delta)$ between the indicators obtained on the first day and after 2 weeks - were calculated and further compared.

Results: During 2 weeks of follow-up, ESR practically did not change (it was 16 [6;48], after 2 weeks 14 [6;27], $p=0.45)$, CRP decreased by 3.5 times $(22.3$ [2.5;40.5] and 5.9 [3.0;23.7], $p=0.4)$, BASDAI (7.2-3.1, $p=0.003)$, ASDAS-CRP (3.7-2.2, $\mathrm{p}=0.001)$ and BASFI (5.5-2.5, $\mathrm{p}=0.001)$, but not BASMI 10 (24-22, $p=0.18$ ). There were also no significant changes in mobility indicators according to sonographic measurements for 2 weeks. However, the correlation analysis of the dynamics of indicators for the study period showed the following results (see the Table 1):

Table 1. Correlation ( $r$ ) between spinal ultrasound parameters and AS activity indices and metrological indices at the beginning of the study and after 2 weeks.

\begin{tabular}{lcccccc}
\hline$\Delta$ of the indicators & $\Delta_{i} \mathbf{C}_{5}-C_{6}$ & $\Delta_{\mathbf{s}} \mathbf{C}_{5}-\mathrm{C}_{6}$ & $\Delta_{\mathrm{i}} \mathrm{Th}_{11}-\mathrm{Th}_{12}$ & $\Delta_{\mathbf{s}} \mathrm{Th}_{11}-\mathrm{Th}_{12}$ & $\Delta_{\mathrm{i}} \mathrm{L}_{4}-\mathrm{L}_{5}$ & $\Delta_{\mathrm{s}} \mathrm{L}_{4}-\mathrm{L}_{5}$ \\
\hline$\Delta$ ESR & $-0.5^{*}$ & $-0.4^{*}$ & -0.3 & -0.2 & $-0.5^{*}$ & $-0.4^{*}$ \\
$\Delta$ CRP & -0.3 & -0.1 & -0.4 & -0.5 & $-0.4^{*}$ & $-0.7^{*}$ \\
$\Delta$ ASDAS & $-0 / 4$ & -0.5 & 0.1 & -0.3 & 0.1 & 0.2 \\
$\Delta$ BASDAI & -0.2 & -0.1 & -0.2 & -0.3 & $-0.3^{*}$ & $-0.5^{*}$ \\
$\Delta$ BASFI & $-0.6^{*}$ & $-0.5^{*}$ & -0.5 & 0.2 & 0.3 & -0.3 \\
$\Delta$ BASMI 10 & -0.2 & -0.1 & -0.2 & -0.3 & $-0.3^{*}$ & $-0.5^{*}$
\end{tabular}

Note: ${ }^{*}-\mathrm{p}<0.05, \Delta \mathrm{i}-\mathrm{C} 5-6$, Th11-12, L4-5, mm - the difference between the indicators obtained by ultrasound in the vertical position at admission and after 2 weeks, $\Delta s-$ the difference between the indicators at maximum sagittal flexion.

A correlation was found between an increase in the interspinous distance in the cervical and lumbar spine and a decrease in the level of ESR, and in the lumbar spine - with CRP. There is also a significant relationship between the activity of AS according to the BASDAI index and the mobility of the spine at the level of L4-5, which was manifested by an increase in the interspinous distance with a decrease in the activity of the disease. Sonographic measurements of all three levels of the spine show a negative correlation with the combined metrological index BASMI 10, most significantly with the L4-5 level of the spine.

Conclusion: The method of ultrasound examination of spinal mobility in AS allows not only to objectify the indicators, but can also be used to monitor the function of the axial skeleton during follow-up.

REFERENCES:

[1] Yurdakul APA, e.a. Medicine: September 2018; doi: 10.1097/ MD.0000000000012609.

Disclosure of Interests: None declared.

DOI: 10.1136/annrheumdis-2021-eular.3541

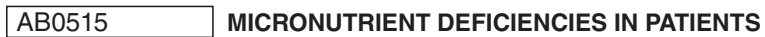 WITH SPONDYLOARTHRITIS: AGE AND GENDER IMPLICATIONS}

P. Triggianese ${ }^{1}$, F. Caso ${ }^{2}$, A. D'antonio ${ }^{1}$, P. Conigliaro ${ }^{1}$, S. Ferrigno ${ }^{1}$, L. Costa ${ }^{2}$, M. Tasso ${ }^{2}$, M. S. Chimenti ${ }^{1}$, R. Perricone ${ }^{1} .{ }^{1}$ Rheumatology, Allergology and Clinical Immunology, Department of "Medicina dei Sistemi", University of Rome Tor Vergata, Roma, Italy; ${ }^{2}$ Rheumatology Unit, Department of Clinical Medicine and Surgery, University of Naples Federico II, Naples, Italy

Background: Micronutrient deficiencies (MNDs) are common among patients with chronic inflammatory diseases. These are associated with a pro-inflammatory status and co-morbidities, and influenced by several factors, such as age and gender. Objectives: No any study has investigated MNDs and their correlation with gender in Spondyloarthritis (SpA). With this purpose, this study analyzed the occurrence of anemia and the status of ferritin $(\mathrm{Fe})$, vitamin $\mathrm{D}[25(\mathrm{OH}) \mathrm{D}]$, vitamin $\mathrm{B} 12$ (B12), and folic acid (FA) in a cohort of patients with SpA.

Methods: Levels of $\mathrm{Hb}, \mathrm{Fe}, 25(\mathrm{OH}) \mathrm{D}, \mathrm{B} 12$, FA, were evaluated in $220 \mathrm{SpA}$ outpatients (137 females and 83 age-matched males) with Psoriatic arthritis (PsA $n=110)$ and SpA $(n=110)$. Disease activity was assessed by DAPSA or ASDAS$\mathrm{CRP}$ as appropriate and functional status was evaluated with HAQ score. Body Mass Index (BMI) was selected as a metabolic clinic parameter.

Results: Male and female patients were similar for disease duration and severity as well as the distribution of diagnosis and treatments (Table 1). In males BMI was higher than in females $(P=0.03)$ and positively correlated with the age $(P=0.01)$. In female patients, $B M I$ directly correlated with $H A Q(P=0.03)$. The prevalence of anemia $(\mathrm{Hb}<12)$ was $13.6 \%$ of the study cohort; half of anemic patients had PsA, the others had enteropathic SpA (ESpA). Anemia resulted almost wholly in female patients (99\%). In the male group, $\mathrm{Hb}$ resulted inversely related to age $(P=0.01)$ and CRP levels $(P=0.008)$. Ferritin was lower in females than in males $(P=0.0003)$. $25(\mathrm{OH}) \mathrm{D}$ deficiency $(\leq 20 \mathrm{ng} / \mathrm{ml})$ was present in $23.2 \%$ of the cohort: males had lower $25(\mathrm{OH}) \mathrm{D}$ than females $(\mathrm{P}=0.02)$. Among male patients disease duration correlated positively with ferritin $(\mathrm{P}<0.001)$ and inversely with $25(\mathrm{OH}) \mathrm{D}(\mathrm{P}=0.02)$. Low levels of serum $\mathrm{B} 12(\leq 200 \mathrm{pmol} / \mathrm{l})$ were rare $(13.2 \%)$, while deficiency in $\mathrm{FA}(\leq 4 \mathrm{ng} / \mathrm{ml})$ was frequent $(22 \%)$ and associated with B12 defect in $31 \%$ of cases, with almost similar occurrence in males and females. A diagnosis of ESpA occurred in $55 \%$ of cases with B12 deficiency and $62.5 \%$ of FA defect, without gender difference. Mean levels of ferritin, 25(OH)D, B12, and FA did not differ significantly between PsA and SpA patients.

Table 1. Data from the study population.

\begin{tabular}{lccc}
\hline & Females $(\mathrm{n}=137)$ & Males $(\mathrm{n}=83)$ & $P$ \\
\hline Age (yrs; §) & $51.65 \pm 13$ & $52.9 \pm 12.8$ & $N S$ \\
BMI (*) & $24[17.2-50.2]$ & $25.8[19.6-43.6]$ & $<0.05$ \\
CRP (mg/l; *) & $2.9[0-53]$ & $2[0-61]$ & $N S$ \\
$\mathrm{Hb}(\mathrm{g} / \mathrm{dl}$; §) & $13 \pm 1.2$ & $14.4 \pm 1.4$ & $N S$ \\
$\mathrm{Fe}\left(\mathrm{mg} /\right.$ /; $\left.{ }^{*}\right)$ & $37[2-148]$ & $64[4-452]$ & $<0.05$ \\
25(OH)D (ng/ml; *) & $28.2[5-67]$ & $25[5-50]$ & $<0.05$ \\
Vitamin B12 (pmol/l; *) & $350[60-990]$ & $313[47-797]$ & $N S$ \\
Folic Acid (ng/ml; *) & $7[1.7-40]$ & $6.9[1.8-39]$ & $N S$ \\
PsA (N/\%) & $73 / 68.23$ & $34 / 31.77$ & $N S$ \\
SpA (N/\%) & $64 / 41$ & $49 / 59$ & $N S$ \\
Concomitant IBD (n/\%) & $56 / 65.9$ & $29 / 34.1$ & $N S$ \\
Disease duration (months; *) & $69[6-540]$ & $76.5[3-768]$ & $N S$ \\
Low D.A. (N/\%) & $62 / 45.25$ & $47 / 56.6$ & $N S$ \\
Moderate-high D.A. (N/\%) & $75 / 54.75$ & $36 / 43.4$ & $N S$ \\
COXIB-inhibitors (N/\%) & $21 / 15.4$ & $8 / 9.6$ & $N S$ \\
cDMARDs monotherapy (N/\%) & $35 / 25.5$ & $10 / 12$ & $N S$ \\
bDMARDs (N/\%) & $81 / 59.12$ & $65 / 78.4$ & $N S$ \\
\end{tabular}

BMI, body mass index; CRP, C-reactive protein; Hb, haemoglobin; Fe, ferritin; $25(\mathrm{OH}) \mathrm{D}$, vitamin D; PsA, psoriatic arthritis; SpA, spondyloarthritis; IBD, inflammatory bowel disease; D.A., disease activity; cDMARDs, conventional Disease Modifying Antirheumatic Drugs; bDMARDs, biological DMARDs; $\S$ mean $\pm \mathrm{SD}$; ${ }^{*}$ median $[\min -\max ]$

Conclusion: Our study describes for the first time the possibility of a relevan prevalence of MNDs in SpA patients. Furthermore, we show that MNDs could be also influenced by gender difference and age. Of note, our findings highlight the importance of a screening focused on MNDs in SpA patients. This could be key in optimizing management of SpA patients, in which inflammatory-dependent dysmetabolism is frequent.

\section{REFERENCES:}

[1] Yamamoto EA, Jørgensen TN. Relationships Between Vitamin D, Gut Microbiome, and Systemic Autoimmunity. Front Immunol. 2020;10:3141.

[2] Charoenngam N, Holick MF. Immunologic Effects of Vitamin D on Human Health and Disease. Nutrients. 2020;12:2097.

[3] Bañuls-Mirete M, Ogdie A, Guma M. Micronutrients: Essential Treatment for Inflammatory Arthritis? Curr Rheumatol Rep. 2020;22:87.

Disclosure of Interests: None declared.

DOI: 10.1136/annrheumdis-2021-eular.3687 